E International

\title{
A Delicate Balance: Mobility and Access Needs, Expectations and Costs
}

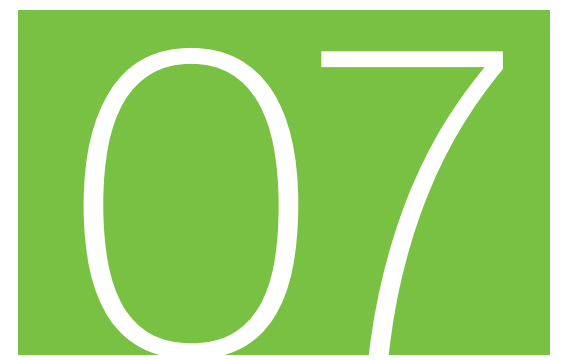

Discussion Paper 2011 07

David METZ

Centre for Transport Studies,

University College London, UK 
This document was produced as background for the 2011 International Transport Forum, on 25-27 May in Leipzig, Germany, on Transport for Society. The views expressed in this document do not necessarily reflect those of the member countries of the International Transport Forum.

Further information about the International Transport Forum is available at www.internationaltransportforum.org 


\section{A Delicate Balance: Mobility and Access Needs, Expectations and Costs}

Discussion Paper No. 2011-7

David Metz

Visiting Professor

Centre for Transport Studies

University College London, UK

April 2011 


\section{INTERNATIONAL TRANSPORT FORUM}

The International Transport Forum at the OECD is an intergovernmental organisation with 52 member countries. It acts as a strategic think tank with the objective of helping shape the transport policy agenda on a global level and ensuring that it contributes to economic growth, environmental protection, social inclusion and the preservation of human life and well-being. The International Transport Forum organizes an annual summit of Ministers along with leading representatives from industry, civil society and academia.

The International Transport Forum was created under a Declaration issued by the Council of Ministers of the ECMT (European Conference of Ministers of Transport) at its Ministerial Session in May 2006 under the legal authority of the Protocol of the ECMT, signed in Brussels on 17 October 1953, and legal instruments of the OECD.

The Members of the Forum are: Albania, Armenia, Australia, Austria, Azerbaijan, Belarus, Belgium, Bosnia-Herzegovina, Bulgaria, Canada, Croatia, the Czech Republic, Denmark, Estonia, Finland, France, FYROM, Georgia, Germany, Greece, Hungary, Iceland, India, Ireland, Italy, Japan, Korea, Latvia, Liechtenstein, Lithuania, Luxembourg, Malta, Mexico, Moldova, Montenegro, Netherlands, New Zealand, Norway, Poland, Portugal, Romania, Russia, Serbia, Slovakia, Slovenia, Spain, Sweden, Switzerland, Turkey, Ukraine, the United Kingdom and the United States.

The International Transport Forum's Research Centre gathers statistics and conducts cooperative research programmes addressing all modes of transport. Its findings are widely disseminated and support policymaking in Member countries as well as contributing to the annual summit.

\section{DISCUSSION PAPERS}

The International Transport Forum's Discussion Paper Series makes economic research, commissioned or carried out at its Research Centre, available to researchers and practitioners. The aim is to contribute to the understanding of the transport sector and to provide inputs to transport policy design. The Discussion Papers are not edited by the International Transport Forum and they reflect the author's opinions alone.

The Discussion Papers can be downloaded from: www.internationaltransportforum.org/itrc/DiscussionPapers/itrcpapers.html

The International Transport Forum's website is at: www.internationaltransportforum.org or further information on the Discussion Papers and other JTRC activities, please email: itf.contact@oecd.org 


\section{TABLE OF CONTENTS}

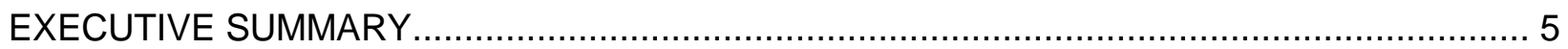

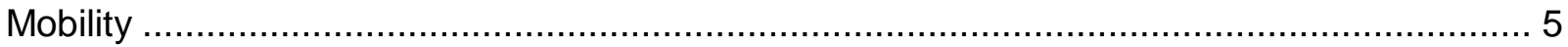

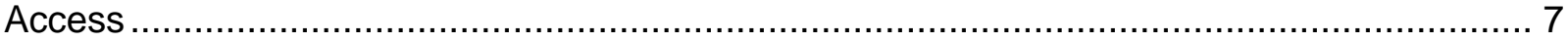

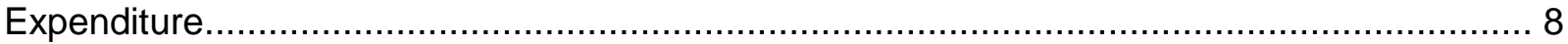

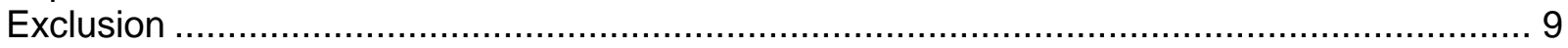

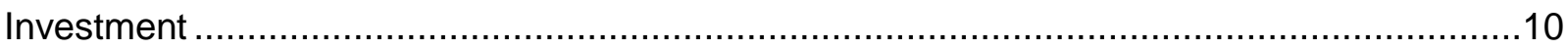

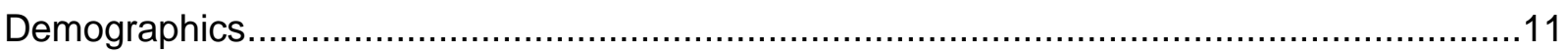

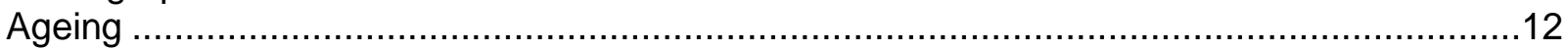

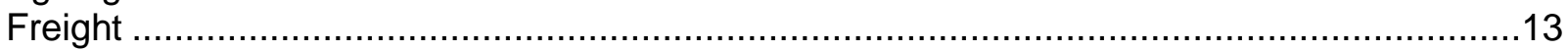

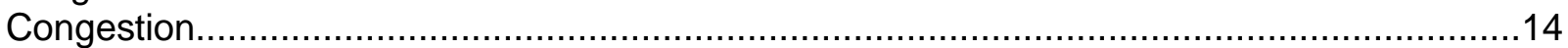

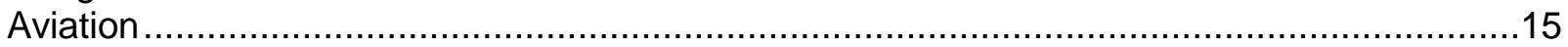

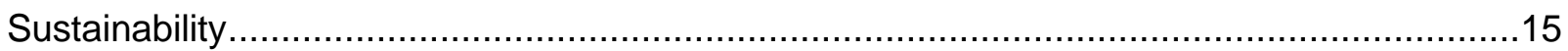

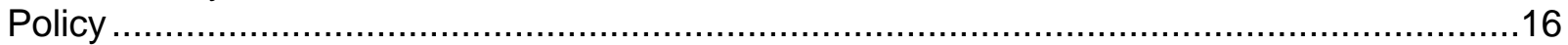

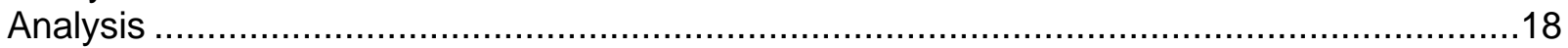

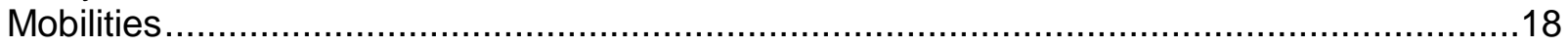





\section{EXECUTIVE SUMMARY}

Mobility has been central to economic development and social progress in the modern era. There is emerging evidence, however, that personal daily travel has recently ceased to grow in developed economies. The historic increase in mobility served to enlarge access to desired destinations and allowed more choice of jobs, homes, shops schools etc within acceptable travel times. Access and choice increase in proportion to the square of the speed, whereas choice of any given kind of destination is characterised by declining marginal utility. Accordingly, saturation of daily travel demand is to be expected and is a likely explanation for the observed cessation of per capita growth of personal travel.

In the absence of per capita growth, overall travel demand and traffic levels will be determined by demographic considerations, in particular population growth and ageing. Much depends on where the additional population live and work. If on greenfield sites, then car-based mobility would be popular. If on brownfield locations within existing towns and cities where the scope for additional traffic is limited, then public transport will be important. London is an example of a city with a growing population where the proportion of journeys by car is in steady decline. Higher population densities improve access, particularly by public transport, walking and cycling. High densities are helpful in respect of the sustainability of the transport sector, in part because this involves less car use and in part because of the scope for electric vehicles, both for rail-based travel and on account of shorter distances travelled by road vehicles. Globally, the world's population is urbanising. If the rapidly growing metropolises can provide commuters with reliable transport, whether, rail, trams or Bus Rapid Transit, they should be able to avoid excessive traffic congestion and become attractive places in respect of both personal mobility and access.

A key policy issue for governments concerned about sustainability is whether to encourage increasing population density in cities, both through the urban planning regime and by financing reliable rail-based (and Bus Rapid Transit) urban public transport. High levels of mobility, access and choice are achievable and affordable in relatively dense urban centres served by high quality public transport. In such situations, use of the private car can play a declining role, with decreasing traffic congestion and vehicle emissions, and increasing scope for carbon reduction through electrification.

Populations are also ageing, in the developed countries in particular. Disabilities in later life result in cessation of driving, with alternatives means needed for mobility and access. More generally, as the majority of people in developed economies achieve sufficient mobility and access to meet their requirements, the focus of government action should be on those who are risk of social exclusion whether on account of old age, youth, disability, poverty or remote location. There is a range of possible interventions, the impact of which can be evaluated by means of accessibility indicators. A policy issue for governments is how much public expenditure to allocate to counter such exclusion.

\section{Mobility}

Two hundred years ago most travel was on foot, with limited and slow horse-drawn transport. Access to facilities was thus severely limited by the time that could be found for travel, within the 24 hour day. Most people spent most of their lives close to where they were born. 
However, over the past two centuries personal mobility has increased markedly as new transport technologies have become available and incomes have grown. Human spatial location and movement has been transformed, a process that started with the early railways and surfaced roads, and has culminated in the personal mobility of the car and the collective mobility of the commercial aircraft, both increasingly widely available.

This transformation of personal mobility has been central to economic progress and modernisation of the industrial and post-industrial eras. It has occurred in parallel with the growth in freight transport powered by a succession of engines - steam, internal combustion, turbine and electric - which have been equally important in making possible modern industrial society ${ }^{1}$.

There are signs, however, that two centuries of growth of travel demand and freight transport may be coming to an end in the developed economies. Let us consider the evidence. Figure 1 shows the pattern of personal daily travel in Great Britain over the past third of a century. This derives from the National Travel Survey which covers all modes of travel except international travel by air (hence the term 'daily travel' since it very largely comprises the journeys we make on a daily basis). ${ }^{2}$ Across the population, the average travel time has held steady at about 375 hours per year, the equivalent of about one hour per day. The average number of journeys made has also stayed constant at about 1000 per person per year (and the purpose of these journeys has also been largely unchanged, with shopping most frequent, followed by visiting family and friends, then travelling to work, education, and personal business). What has changed over the period is the distance travelled rising from 4500 miles (7 $250 \mathrm{~km}$ ) per person per year in the early 1970s, to 7000 miles $(11250 \mathrm{~km})$ by the mid-1990s.

Figure 1. Average distance travelled (miles), travel time (hours) and trips, per person per year

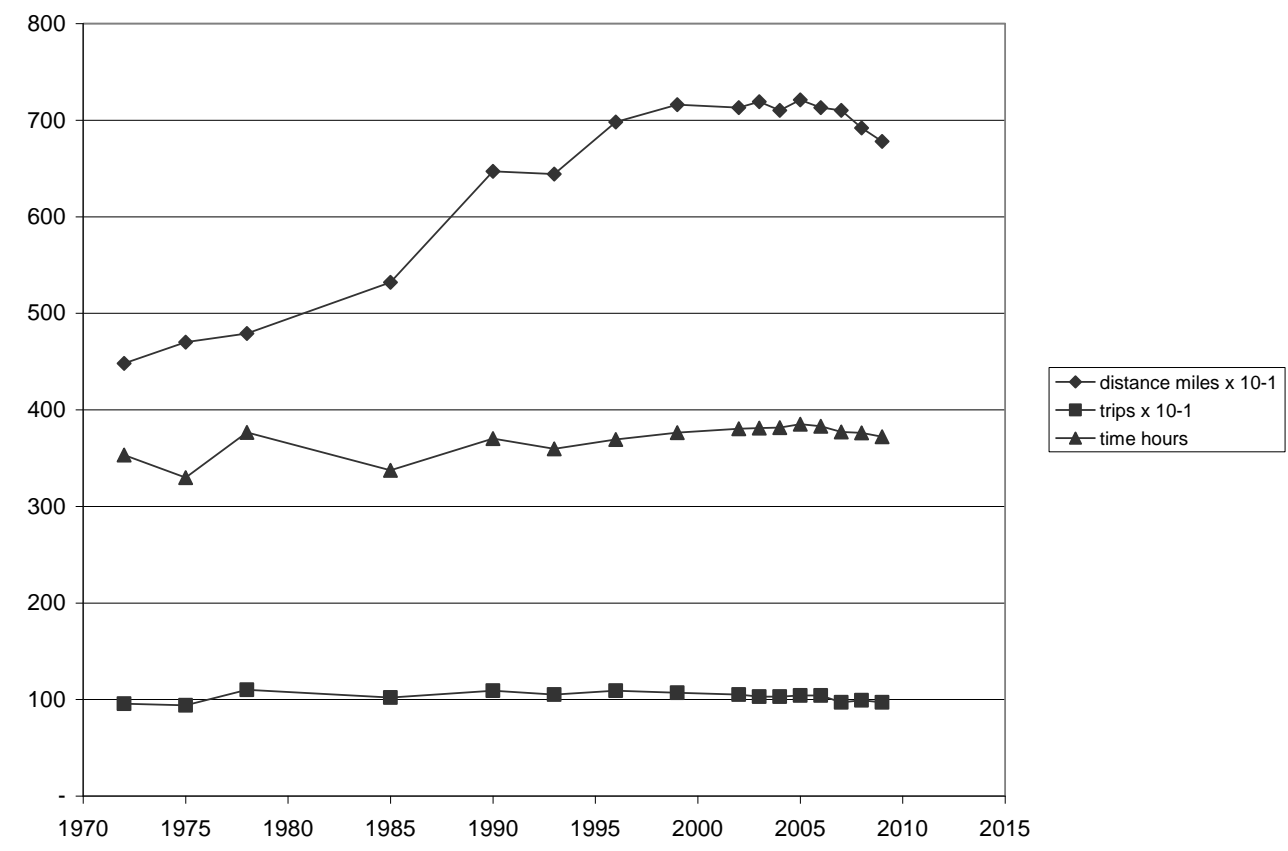

Source: Great Britain National Travel Survey 2009.

1. Crozet (2010).

2. See Metz (2008a) and Metz (2010) for discussion of the National Travel Survey. 
This growth in average distance travelled reflects the way the benefit of investment in the transport system has been taken - in the form of enhanced access to more distant destinations. This has largely been the consequence of more and better cars operating on more and better roads (together with a contribution from improved railways), permitting higher average journey speeds, and thus greater access to desired destinations in the time people have available for travel - which turns out to be an hour a day on average.

The relative constancy of average travel time at an hour a day seen Figure 1 is not unique to Britain but is found generally for all populations investigated. This noteworthy finding may reflect common human needs and constraints operating across most societies - the need for mobility to gain access to activities beyond the home and the constraints of the 24 hour day within which all activities have to be fitted.

Another noteworthy feature of the data in Figure 1 is the lack of change in distance travelled since about 1995 (other than a downturn in the last two years, probably reflecting the economic recession). After two centuries, growth of average distance travelled appears to have ceased. This is also not unique to Britain, at least in respect of travel by the dominant mode, the car. Vehicle miles travelled per capita ceased to increase in the US in 2000, while growth of total motorised per capita passenger travel in eight developed countries seems to have levelled out. ${ }^{3}$ (Again, international travel by air, which continues to grow, is not included in these findings.)

\section{Access}

Why has the growth of personal daily travel apparently come to an end? The available evidence indicates that growing traffic congestion is not on such a scale as to be the main cause, nor are changes in incomes or fuel prices, nor has increasing air travel substituted significantly for daily travel. Rather, the explanation lies in the purpose of daily travel, which is to gain access to the destinations that are part of the daily routine - shops, employment, schools, family and friends and so on. Over many years, people have visited these same kinds of destinations with the same frequency, taking about the same amount of time. As we have been able to travel faster, we have been able to travel further, which has given us more choices choices of jobs accessible from where we live in the time we have available for travel, choices of homes accessible from where we work, choice of shops, schools and so on. Access and choice increase with the square of the speed of travel - because what is accessible falls within a circle whose area is proportional to the speed. On the other hand, the value of each extra element of choice of a given kind of destination may be expected in general to decline - this is the principle of diminishing marginal utility. ${ }^{4}$

This combination - of access and choice increasing with the square of the speed and choice subject to diminishing marginal utility - leads to the expectation that demand for travel to these routine destinations would cease to increase because we have sufficient choice. We might say that demand has saturated.

There is some evidence about access consistent with the idea of travel demand saturation. For instance, data on accessibility of family doctors in England are shown in Table 1, for two journey times (15 and $30 \mathrm{~min}$ ) and for two modes of travel (public transport and/or walking, and car). For people without a car living in rural areas, the choice of doctors within 15 min may be

3. Puentes and Tomer (2008); Lucas and Jones 2009; Millard-Ball and Schipper (2011)

4. See Metz (2010) for a discussion of travel to different kinds of destination, including certain exceptions to the rule of diminishing marginal utility. 
limited to one or two, whereas in dense urban areas, a choice of four or more is common. On the other hand, nearly everyone with a car has a choice of five or more doctors within 15 min drive. For those without a car, increasing the journey time to $30 \mathrm{~min}$ allows choice of four or more doctors for most people. ${ }^{5}$ Another study assessed the choice of large supermarkets in urban areas of Britain for people with a car. For a journey time of 15 minutes, $80 \%$ of the population had a choice of three or more supermarkets, and $60 \%$ had a choice of four or more. ${ }^{6}$

Table 1. Access to family doctors. Number of local authorities with access for households to average number of doctors as a function of mode and time of travel (PT = public transport)

\begin{tabular}{lrrrrr}
\hline Number of doctors & 1 & 2 & 3 & 4 & 5 \\
15 min PT/walk & 81 & 98 & 74 & 66 & 34 \\
15 min car & 0 & 2 & 0 & 10 & 341 \\
30 min PT/walk & 0 & 15 & 47 & 90 & 201 \\
30 min car & 0 & 0 & 0 & 0 & 353 \\
\hline
\end{tabular}

These relatively high levels of choice of doctors and supermarkets are also found for primary, secondary and tertiary schools, for hospitals, and for employment generally. The implication is that people who live in developed economies, and who have use of a car or frequent public transport services, have sufficient choice of routinely accessed facilities such that their demand for daily travel is approaching, or may have reached saturation. (For non-routine travel, such as holiday trips, there may still be unmet demand, hence the continued growth in air travel.)

I propose therefore that a 'natural' limit to daily travel may have been reached for most people in developed economies who are relatively unconstrained in their personal mobility because they have the use of a car or a good public transport system. I suggest that this is a 'natural' limit because it arises from satisfied needs, rather than from external constraints such as traffic congestion, damage to the environment or prohibitive costs. The concept of such a natural limit to travel is novel and not uncontroversial. If substantiated by further investigation, the concept would be important both for decisions on the scale and nature of future investment in the transport system, and would help alleviate concerns about sustainability.

\section{Expenditure}

Household expenditure and travel and transport increases as incomes rise. In low income countries, households without a car devote on average $3-5 \%$ of their income to travel. As incomes grow, cars become affordable and travel expenditure rises with increasing car ownership, stabilizing in the range 10-15\% once ownership reaches about one car per household. ${ }^{7}$ It seems that households attach priority to acquiring the first car, but not subsequent cars. Arguably, $10-15 \%$ of household income devoted to travel represents an affordable level for developed economies. However, the point of stabilisation within this range depends on the level of transport subsidies and taxes. High levels of tax on road fuel and low subsidies for public transport push household expenditure on travel towards the top of the range (as in Britain where

5. Analysis of 353 local authorities covering all of England, Metz (submitted for publication).

6. Competition Commission (2008).

7. Schafer and Victor (2000); Kauppila (2011). 
$16 \%$ of household expenditure is on travel). Although there are perspectives in respect of transport taxes and subsidies based on economic theory ${ }^{8}$, in practice political judgment in the light of revenue implications tends to dominate, not least because significant changes in such taxes and subsidies are often politically sensitive.

When changes in transport taxes and subsidies are contemplated, the position of low income households becomes a focus of attention, given the presumed unavoidable nature of much daily travel. In the energy sector, a political concern for governments is 'fuel poverty', which is said to arise when in order to heat a home to an adequate standard of warmth a household needs to spend more than $10 \%$ of its income on total energy use. 'Travel poverty' seems not yet to have emerged as a general issue but could become significant if travel expenditure were to grow in consequence of higher oil prices arising from scarcity, together with incorporating the costs of carbon abatement both as a carbon-related charge and through new technologies. The impact on the wallet of the road user is a political deterrent to the wider use of charges for road use to tackle congestion, despite its theoretical attractiveness and the feasibility demonstrated by urban schemes in a number of countries

\section{Exclusion}

We have, at least for the developed economies, a situation in which daily mobility allows a substantial part of the population considerable access to and choice of the main kinds of frequently used destinations at affordable cost. There are, however, substantial minorities of the old, the young and the poor who are at risk of being excluded from full participation in society through lack of the use of a car or good public transport. This is particularly serious when access to employment, education and health services is limited. As demand for daily travel of the majority is increasingly met, the concerns of the excluded thus move to centre stage.

There is range of interventions to mitigate shortfalls in access, including improving the scope and frequency of public transport; cheaper or free public transport for those on low incomes; and fostering assistive technologies such as electric mobility scooters for people with ambulatory disabilities. Until recently, it has been difficult to assess the magnitude of the remaining problem of lack of mobility and therefore difficult to decide what further interventions by government would be justified. Progress is now possible with the availability in Britain of Accessibility Indicators, mentioned above in respect of choice of doctors etc.

Accessibility Indicators are intended to help local authorities develop accessibility strategies which involve meeting targets for access of their population to services and employment by public transport, walking and cycling. ${ }^{9}$ This approach stems from a study of the links between social exclusion, transport and the location of services which led to a new framework for accessibility planning. Destination Indicators look at the proportion of the resident population that can access a service within a certain time, while Origin Indicators address the opportunities and choices available to a target population in a particular area. The target population is the subset of the resident population relevant for the trip purpose, for instance the target population for primary schools is children 5-10 years old. Use of these Indicators should help address problems of exclusion through lack of mobility and access by helping identify particular vulnerable groups of people, defined by spatial location and socio-economic status, which could benefit from specific improvements in public transport or assistance with the costs of travel.

8. Sansom et al (2001).

9. www.dft.gov.uk/pgr/statistics/datatablespublications/ltp/coreaccessindicators2009 
A further class of mitigations of lack of access arises from the use of information technology, including online shopping and keeping in touch with family and friends through an increasing range of mobile and broadband IT devices. It is noteworthy that driving licence holding amongst young men in Britain has been declining in recent years. For men in their thirties, licence holding has held steady at above $85 \%$ since 1975 , whereas for men in their twenties there has been a significant decline since the early 1990 s to $67 \%$ at present. While the cost of car ownership is undoubtedly a factor, we might speculate that the ability to be in almost continuous virtual contact with members of the social network reduces the need for face to face engagement and hence for travel. Until recently, there has been little evidence for any net impact on travel demand arising from developments in information and telecommunications technologies, but it is possible that this could changing, with substitution now beginning to occur.

In developed economies, social exclusion arising from lack of mobility affects a minority. In developing economies, such exclusion is widespread, which is a compelling argument for investment in the transport system to enhance mobility and access. But investment demands financing and the need to earn a return - whether social or commercial - on the funds committed. The costs of constructing and operating the transport system fall on both travellers and on the tax payer. The questions are how much to spend, on what modes of transport, in what locations, at whose expense?

\section{Investment}

Investment in the transport system accounts for a significant element of public expenditure for most countries. Governments take seriously the expectations of their populations as regards the need for mobility and accordingly need to decide criteria for prioritising investment. As discussed above, the growth in average distance travelled shown in Figure 1 reflects the way the benefit of investment in the transport system has been taken in the form of enhanced access to more distant destinations, a consequence of higher average journey speeds in the more or less unchanging time that people make available for travel - on average an hour a day. This conclusion contrasts with the standard assumption used by transport economists that the saving of travel time is the main benefit of investment, which, because time saved has value, allows the ratio of monetary benefits to costs to be estimated and used in investment appraisal. However, time saving benefits do not correspond to the actual long-run outcome and moreover disregard the spatial and social distributional consequences of transport investment. Public investment in transport systems allows access to land which thus becomes suitable for development for commercial and residential uses by private sector enterprises. It is this economic gain from property development that is the main source of the benefit from transport investment, gain which is found in specific locations, which is retained in part by land owners and developers and which accrues in part to businesses. ${ }^{10}$

A clear example of the relationship between public investment in transport and private investment in property development is in London's Docklands, which were abandoned by the shipping industry following introduction of containers. Public investment in the Docklands Light Railway, a metro, put the area on the map, showing the ease of access (ten minutes) to the City, the traditional financial district. This catalysed privately funded commercial property development to construct a second financial district at Canary Wharf, which has changed the landscape of East London, with the tallest building in Britain and office space and facilities for 100000 employees.

10. The perspective outlined in this paragraph reflects an emerging critique of the standard approach of transport economics, see Metz (2008a) for the critique and Mackie (2010) for a partial response. 
Investment in the transport system can have a variety of objectives: to promote economic and urban regeneration; to reduce carbon emissions and other detrimental impacts; and to enhance the safety and comfort of travellers. The challenge is to make the best use of public funds, particularly at the present time of difficulty in the wider economy. A focus on costeffectiveness in achieving agreed objectives is a sensible approach, with options not limited to transport investments, as for instance is applied to appraisal of technologies for reducing carbon emissions - where the potential of both transport and non-transport investments are assessed by means of Marginal Abatement Costs, the cost per tonne of carbon avoided and hence a measure of cost-effectiveness.

\section{Demographics}

Future growth in travel demand and traffic levels in developed economies will be increasingly driven by population growth, given the emerging evidence that per capita daily travel is stabilising. Much depends on whether the additional population is accommodated in housing on greenfield or brownfield sites. New houses on greenfield sites, on the edge of existing settlements, has been the main way in which towns and cities have expanded historically, taking advantage of improved transport to link the new suburbs to the central business district. Greenfield housing is associated with car use for daily journeys, including commuting to non-central locations.

Brownfield development occurs on existing developed land, such as the redevelopment at higher density of deteriorated inner city areas. It also reflects intensification of use of existing urban property when larger houses are subdivided. In town and cities there is little scope to add road space and hence brownfield development is associated with increasing use of public transport. As an example, consider London, an economically and culturally vibrant world city which has been experiencing population growth in recent years.

At the beginning of the nineteenth century the population of London was one million. It grew to over six million by the beginning of the twentieth century, reaching a peak of over eight million by mid-century. There was then a period of decline, with a loss of $1.2 \mathrm{~m}$ during the $1960 \mathrm{~s}$ and 1970s, as small town and rural lifestyles became more popular. After a period of stability in the 1980 s, London's population has grown steadily from $6.8 \mathrm{~m}$ to reach $7.6 \mathrm{~m}$ by 2008 . The forward projection is for continued growth, with around $1.3 \mathrm{~m}$ more people and more than 750000 additional jobs by 2031. Population growth has been within the existing urban boundaries, such that $96 \%$ of capacity for new housing comes from formerly used sites.

Population growth in London over the past two decades has been accompanied by declining relative car use and increasing popularity of public transport. Figure 2 shows estimates made by Transport for London of share of journeys by mode, 1993-2008: private transport has been declining while public transport use has been increasing, with walking and cycling staying level. Note that the total number of car-based trips - driver and passenger - has held steady over the period at about $10 \mathrm{~m}$ per day, consistent with a fixed amount of road space, but the share of car-based journeys has fallen on account of population growth. Private transport mode share is projected to decline to $37 \%$ by 2031 , compared with peak car use in London of $50 \%$ of all trips in the early 1990 s.

This trend of declining mode share of car use in London is remarkable. Historically and globally, as incomes have grown so has car use. Yet in London, a city with a dynamic economy and median incomes in the inner boroughs 50\% above the national average, this trend has gone into reverse. Moreover, the Mayor of London's Transport Strategy projects continued population growth and continued decline in car mode share, based on substantial investment in public 
transport, both rail and bus, and also encouragement of walking and cycling. Thus there is nothing inevitable about the relationship between car use and income, a conclusion helpful for concerns about sustainability.

Figure 2. Trip based mode share by main mode in London.

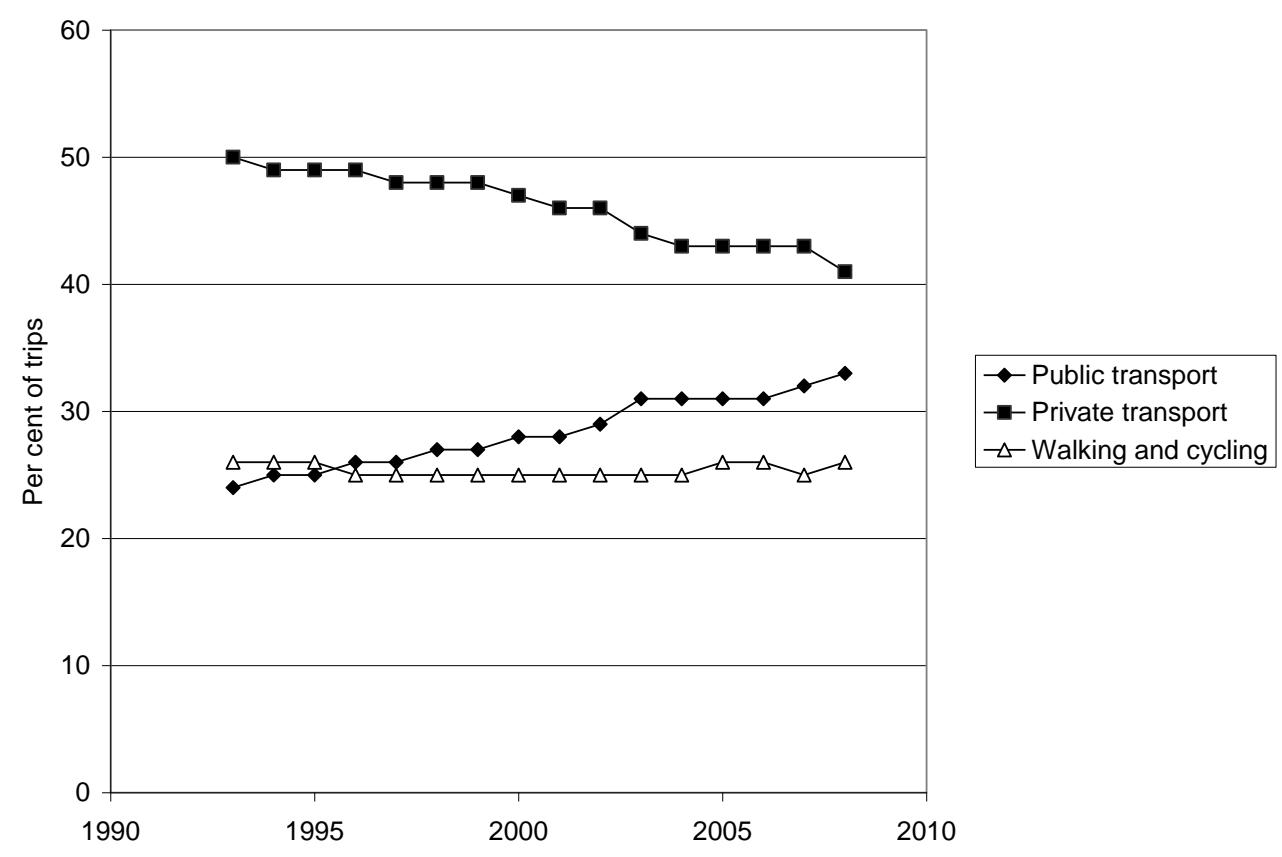

Source: Transport for London.

\section{Ageing}

The populations of most countries are not only growing - they also are ageing. For instance, the proportion of the population of Britain age under 16 years is officially projected to fall from $18.8 \%$ to $17.8 \%$ over the period 2008-2035, while the proportion age 65 and over increases from $16.2 \%$ to $22.9 \%$. In the longer run, the proportion over age 65 is sensitive to assumptions made about life expectancy, fertility and migration, and by 2080 could be in the range $20-35 \%$.

The ageing of the population arises from two main developments: life expectancy is increasing, and the baby boom generation is approaching later life. The implications of a larger cohort of older people, the baby boomers, might be projected on the assumption that their travel behaviour would be similar to earlier cohorts, allowing for trends such as the increase in the proportion of older women holding a driving licence. However, life expectancy has been growing rapidly - period life expectancy at birth in Britain has increased by more than two years per decade in recent years and is projected to continue to increase in the coming years. The question that arises concerns the propensity to travel in these extra years of later life, which depends importantly on health status.

Debate continues about whether late life disability is increasing or decreasing; the balance of evidence suggests that deterioration is being postponed, so that levels of health that used to be prevalent at age 70 now prevail at age $80 .{ }^{11}$ One implication is that people will continue to drive until more advanced ages, given the attractions of the car for gaining easy access to

11. See for instance Vaupel (2010). 
desired destinations. On the other hand, the larger baby boom cohort will mean greater numbers reaching the point when people give up driving on account of the impact of multiple minor morbidities - musculo-skeletal, sensory and cognitive. This in turn implies a greater need for provision of alternative means for providing mobility and access.

The implications of an ageing population for transport provision have attracted increasing interest. ${ }^{12}$ Mobility is important for quality of life, and loss of mobility in later life is detrimental, not just in respect of access to desired destinations, but also loss of the incidental benefits - getting out and about, exercise and social engagement. ${ }^{13} \mathrm{~A}$ key issue is the timing of giving up driving, at which point alternative means of mobility and access are then needed, the demand for which will increase as the population ages. One response has been the provision of cheaper or free off-peak travel on buses for older people - a benefit which is popular but arguably not efficiently targeted on those most in need. Another is the growing use of pavement-running mobility scooters, well suited to preserving personal mobility in dense urban areas for those with ambulatory disabilities.

\section{Freight}

The road network is shared by personal travellers and freight vehicles. Freight movement by heavy goods vehicles has historically grown in parallel with the growth of GDP, and this continues to be the case for the European Union states as a whole. ${ }^{14}$ In the UK, however, road freight transport (tonne $\mathrm{km}$ ) has uncoupled from the growth of GDP, although use of light goods vehicles remains buoyant. Figure 3 shows the growth of freight moved on roads in Britain by Heavy Goods Vehicles, where tonne-km decoupled from GDP in the late 1990s (the recent effect of the recession is particularly visible).

Figure 3. Growth of GDP and road freight tonne-km in Great Britain $(1980=100)$

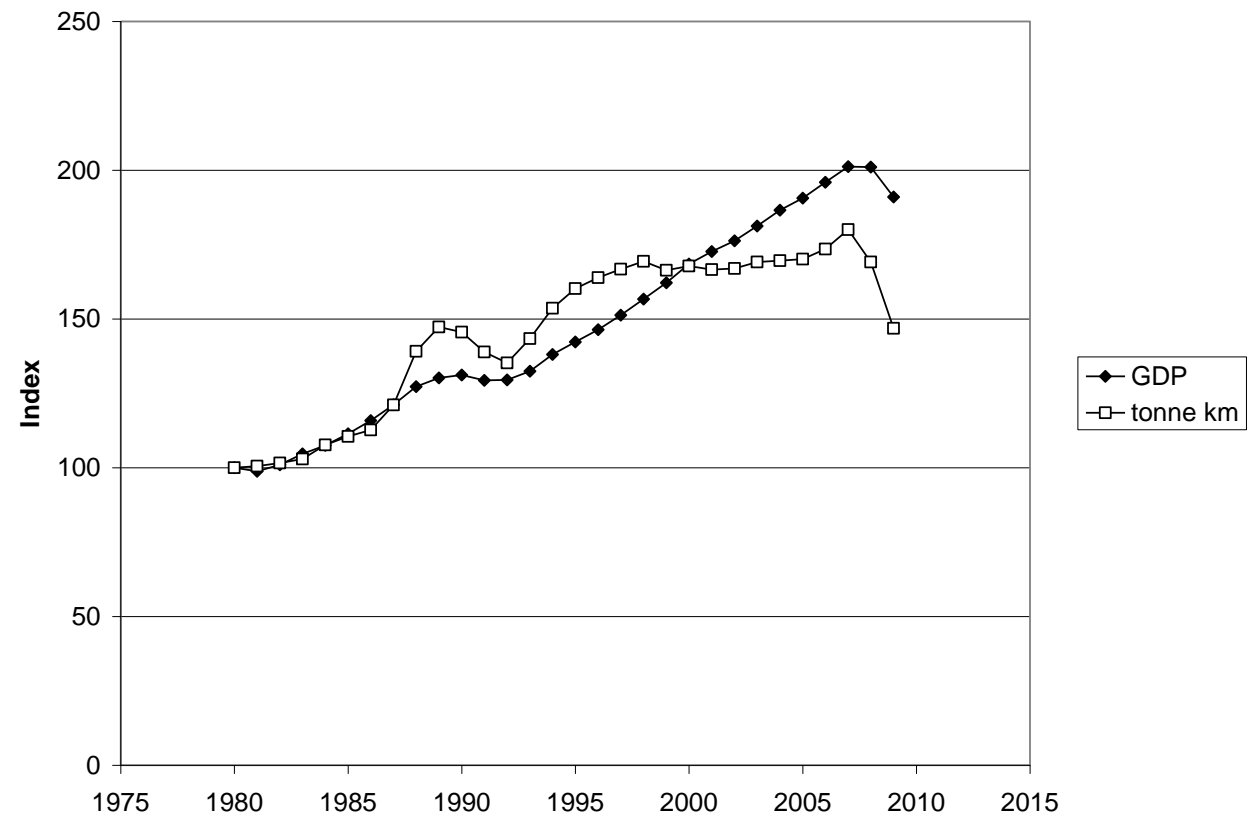

12. Metz (2003); Schwanen and Paes (2010).

13. Metz (2000); Banister and Bowling (2004).

14. Eurostat (2009). 
Both the cessation of growth of personal travel and of road-born freight transport arose at about the same time (the mid-nineteen-nineties) in Britain, even though real personal incomes and GDP have continued to rise (Figures 1 and 3 ). This suggests the possibility of a common cause for both kinds of decoupling. The cessation of growth of personal travel has been attributed to a saturation of demand for daily travel on account of the high levels of access and choice available from modern transport systems, as discussed above. There are a variety of possible reasons for freight transport/GDP decoupling, including recognition that the spatial concentration of economic activity has traditionally been one of the main drivers of road freight growth, but that this process is now at an advanced stage and cannot continue indefinitely. ${ }^{15}$ In effect, the development of the modern trunk road system has allowed improved access to retail outlets for the freight distributors, using fewer, centrally-located warehouses, thus saving inventory and estate costs - a process in which returns inevitably diminish, leading to demand saturation.

The prospects for freight transport depend on many factors, including the growth and location of the population, scale of sourcing from abroad, as well as changes in the composition of consumer goods arising from digitisation and miniaturisation. The possibility of saturation of demand for consumer durables needs also to be recognised, given the high levels of household ownership in the developed economies of items such as washing machines, microwave ovens, and fixed and mobile phones, with satellite television, home computers and broadband internet expected to reach high levels of penetration. These markets are in transition from growth to replacement. ${ }^{16}$

\section{Congestion}

Road freight and motorists compete for space on congested roads. Constructing new roads or additional carriageway has not solved the problem of congestion since additional traffic has emerged - 'induced traffic'. This has arisen because people have taken the benefit of the higher speeds possible as congestion has initially eased to make longer trips in the time available, hence more vehicle-kms, more emissions and congestion in due course restored. What has been gained is access, not reduced congestion. The suggestion offered earlier that demand for daily travel may be reaching saturation does not exclude the possibility, however, that future investment in road capacity might allow some reduction in congestion.

Another approach to tackling congestion is through road pricing, whereby those attaching low value to their journeys at time of congestion are priced off the network. Although "congestion charging' has been implemented successfully in Central London and elsewhere ${ }^{17}$ it is generally politically unpopular, in part because the potential losers complain more loudly than the potential winners cheer. The losers include low wage motorists for whom the car is essential for the journey to work on account of lack of public transport.

To deal effectively with traffic congestion, it is important to understand both the scale of the problem and the main detriment. When asked in surveys, only about a quarter of British road users report that congestion is a problem on their most frequent journeys all or most of the time, while motorway users say that the main problem is uncertainty of journey time. ${ }^{18}$ It is possible to

\footnotetext{
15. McKinnon (2007).

16. Osenton (2004).

17. JTRC (2010).

18. DfT (2010).
} 
reduce such uncertainty by means of better information about estimated journey times, taking advantage of real time and predicted traffic data, building on existing services provided through GPS and other navigation aids. The most efficient freight operators are committed to delivering to customers within a 30 minute window and are able to anticipate traffic conditions sufficiently well to achieve such targets. The technology needs to be extended to the private motorist who would thus be enabled to time the start of the trip to arrive as planned. IT-based approaches to mitigating the effects of congestion are likely to be more cost-effective and publicly acceptable than directly tackling congestion itself.

\section{Aviation}

Air travel continues to grow, helped by the low prices offered by the budget airlines. Air travel at speeds five to ten times faster than surface travel opens substantially more distant access opportunities for individuals and families. Leisure travel dominates, with people in Britain making on average about one round trip a year by air, for holidays or to visit family and friends. This market seems far from saturated.

However, the average of one round trip by air a year conceals wide variation. Recent surveys in Britain show that half the population did not fly in any one year - the 'infrequent flyers'. The frequency of air travel increases from lower to higher socio-economic status groups; younger people and older people travel less often than those in mid-life; and air travel rises with income. Nevertheless, a quarter of those in the highest income quintile took no flights in the previous year. The prospects for the growth of demand for air travel depend importantly on whether these 'infrequent flyers' are likely to change their habit in the future. This group is certain to be heterogeneous. Some people have never flow; some fly but rarely; others regularly take annual holidays abroad but may have missed a year for a particular reason such as illness. Some current infrequent flyers may have flown frequently in an earlier phase of life. We need to understand the motivations for not flying in order to assess the likelihood that the current infrequent flyers may take flight more often in the future, and hence the prospects for growth of air travel.

Conventional travel demand projections, based on extrapolation of past trends and assuming income growth, find it difficult to allow for market maturation, as for instance the standard models of daily travel behaviour which do not generally project demand saturation. There is therefore a need to investigate the behavioural heterogeneity of the market for air travel to allow more precise model calibration. If the infrequent flyers are set in their ways, demand for air travel may be nearer saturation than is usually supposed.

\section{Sustainability}

The transport sector is usually regarded as problematic as regards its contribution to carbon emissions and climate change, in that it is assumed that travel demand will continue to grow as incomes increase and that the opportunities to reduce consumption of oil-based fuels through switching to non-fossil fuel generated electricity will be costly to realise. However, the needs of the population for mobility and access will be easier to meet if, as argued above, the demand for daily travel is no longer growing in the developed economies, and if population growth is accommodated largely in urban areas where public transport is both more efficient and sustainable than the car.

In recent years, there has been a growing interest in a range of transport policy initiatives designed to influence people's travel behaviour away from single-occupancy car use and towards more benign and efficient options, through a combination of marketing, information, 
incentives and tailored new services - sometimes described as 'Smarter Choice' measures. Such measures include workplace and school travel plans, personalised travel planning, information and awareness campaigns, car clubs and car sharing schemes, and tele-working, conferencing and - shopping. It has been concluded that Smarter Choice measures have the potential to reduce national traffic levels by about $11 \% .{ }^{19}$ However, it has not been possible to demonstrate this scale of traffic reduction empirically in situations where such measures have been implemented. In part this may be because of traffic uninfluenced by the implementation, such as commercial vehicles and through traffic, and in part because a reduction in car use by some drivers may be offset by greater use by others who take advantage of the reduced congestion to make more and/or longer trips.

Hence there is a need to 'lock in' the benefits of the 'soft' behavioural interventions by complementary 'hard' measures that result in, for instance, reallocation of road capacity to buses, cyclists or pedestrians and parking controls. However, the question is then which kind of intervention is the more important. Arguably, it is the hard measures that really matter - these have teeth. The soft measures would be seen as facilitating - helpful but not essential since people would learn to adapt to the hard measures in any event. From this perspective, it is the interventions which oblige behavioural change that can be relied upon to reduce traffic and carbon emissions. The interventions that only incentivise behavioural change persuade some people but not all, thus allowing a 'rebound' in the forms of more and/or longer car journeys by those not persuaded.

A further constraint on behavioural measures to reduce car use is that access is thereby reduced for those for whom the car provides the quickest door-to-door journeys. It is likely that those who are persuaded to give up the car are those for whom such user benefits are smallest at the time, on account for instance of living conveniently close to work, or not having children to escort. If circumstances change - a new job or a new child - these people could be back in their cars, although there would be others for whom circumstances changed the other way who could be targeted for the Smarter Choice treatment. Nevertheless, despite the limitations, measures to encourage behavioural change are still worth considering as part of the range of interventions needed to increase the sustainability of the transport sector. Both older people and younger people could be new target groups for Smarter Choice campaigns. Older people may be persuaded to give up the car earlier, and younger people to defer car ownership for longer, if the needs for access and mobility of both groups could be met adequately in other ways.

\section{Policy}

An effective transport policy requires a good understanding of travel behaviour, past, present and future. It is particularly important to recognise reasons why the future may be different from the past. There is emerging evidence that the developed economies are coming to the end of a long period of growth of demand for personal travel, and possibly also for road freight transport. The reason for this cessation of growth lies in the high levels of access and choice made possible by the modern means of mobility. Time is always a constraint on the amount of travel undertaken, but this constraint has been overcome by speed, as a succession of faster modes of travel became available, the consequence of innovative technologies and higher incomes that made them affordable. Those in the developed economies having available personal motorised transport or good quality public transport are able to exercise considerable choice in daily activities dependent on travel, in particular of employment, residence, shops, educational, health and leisure facilities and so forth. There are therefore reasons to suppose

19. Cairns et al (2008). 
that the per capita demand for daily travel has saturated, or is approaching saturation, and that zero growth would be an arguable assumption for a business-as-usual planning scenario in a developed economy.

If per capita daily travel ceases to grow, then total travel demand and traffic would be driven by population growth. Accordingly, the impact of demographic change, both the increase in total population and in the numbers in later life, has implications for transport investment. A growing population housed on greenfield sites would depend largely on the car, and will need more and better managed road capacity. Additional population on brownfield sites within existing urban areas, where scope for creating additional road capacity is very limited, would need to use public transport as well as walking and cycling - hence the need for more and better local buses for young and old ${ }^{20}$; urban and commuter rail and Bus Rapid Transit for reliable work-related journeys; and high speed rail for city centre to city centre travel.

In recent years, residential growth in Britain has been substantially in city living developments in urban cores. Government policy has been successful in focusing new developments on brownfield land and in cities and in achieving an increase in residential density. Nationally, $80 \%$ of new dwellings in recent years have been on previously developed land. The intensification of high density suburbs and inner city renewal has provided in excess of $95 \%$ of all new dwellings in London.

Meeting the access needs of a growing urban population mainly by means of improved public transport serves wider policy objectives associated with sustainability. It helps constrain the growth of carbon emissions from the transport sector, both by substituting for car use and facilitating electrification. It better meets the needs of non-car owning younger and older people, as well as reducing traffic congestion and promoting economic development. These aspects are facilitated by an integrated approach to policy, for instance as provided by the governance arrangements for London which give the Mayor responsibilities for oversight of economic development, housing and land use as well as transport. The Mayor's Transport Strategy projects employment growth very largely in the inner boroughs, hence the need for investment in radial rail-based schemes.

Globally, the transport sector has generally been seen as less tractable than other sectors of the economy in respect of reducing greenhouse gas emissions, with electric drive trains for road vehicles and supporting infrastructure being technologically challenging and costly. However, there are two emerging lines of evidence which point the other way. First, there is the cessation of per capita growth of daily travel in developed economies, as discussed above. Second, there is the global trend to urban living, with $50 \%$ of the world's population now resident in urban areas, up from $36 \%$ in 1970 and projected to grow to $70 \%$ by 2050 . The experience of London, involving a declining share of journeys by car while population and prosperity are both increasing, potentially has implications for other major urban centres. A high quality public transport system, particularly rail-based for journey time reliability and low emissions, can serve to constrain the historic growth of private transport, even amongst those who can readily afford to own a car. It is noteworthy that London's new financial centre, at Canary Wharf in the former Docklands, has been made possible by new high quality rail transport, which has proved acceptable, despite overcrowding at times of peak use, to the well-paid staff of the international businesses that have chosen to locate there. There are only 3000 car parking spaces for a working population of 100000 .

20. Mees (2009) argues that bus transport can be viable in low density suburbs. 


\section{Analysis}

The transport sector has developed a substantial body of theory and methodology to aid decisions by policy makers. There are, however, weaknesses in the current system of transport analysis which need to be tackled, summarised as follows:

- Use of travel time saving as the main benefit of investment in the transport system is problematic since there are no time savings on average in the long run. The real benefit is enhanced access which brings land into use, with locational and social distributional consequences. We need to have regard to the message of behavioural economics that actors in the real world do not behave as the idealized utility-maximising participants of standard economic frameworks.

- Transport models which neglect land use changes are limited in their usefulness, given the importance of such changes in the response to transport investment. Transport models which take account of such changes are difficult to calibrate and validate and therefore cannot be relied upon.

- Cost-benefit analysis of transport investments, based on time savings, has become excessively elaborate and yet neglects locational and distributional outcomes. Comparable analysis of transport taxes and subsidies is lacking, despite the important impact these have on travel behaviour. Cost-benefit analysis, based on real outcomes, has a role in helping set strategic objectives. Cost-effectiveness analysis may be a simpler and more policy-relevant approach to appraising individual projects designed to achieve such objectives.

- Access, as the main benefit of transport investment, has been relatively neglected in analysis on account of the mistaken focus on time saving. However, relevant data sets of accessibility indicators are now available. Policy interventions that address shortfalls in access of excluded groups are open to appraisal and evaluation.

- Economic appraisal of transport taxes and subsidies has been relatively neglected in comparison to appraisal of capital projects, yet these interventions affect the amount of travel and relative mode share.

- There is a deficiency in the governance of the professional area of transport analysis in that standard setting is dominated by government bodies, with no independent professional oversight as is customary in other areas.

\section{Mobilities}

The mobility discussed thus far has had the purpose of gaining access to desired destinations. However, mobility is not just about getting from A to B. There are other satisfactions from being on the move, out and about, exercising the legs, interacting with other people, engaging with the local community and with society at large. These are benefits of mobility that are independent of the destination, that are central to many leisure pastimes hiking, cycling, skiing and other 'wind through the hair' activities that people are willing to pay for - as well as being incidental to much daily travel. Loss of mobility that comes with old age thus results in loss of quality of life, but not just because of loss of access to shops and other necessary facilities. 
One noteworthy feature arising from investigation of human mobility is the finding that, for any population, average travel time is about an hour a day. As speeds of travel have increased, people have not chosen to reduce the amount of time spent travelling. Part of the reason is to take advantage of enhanced access and choice, but another contributing factor may be that we like to be on the move, for the intrinsic satisfactions of mobility. This may have evolutionary roots. $^{21}$

Humans originated in Africa and have migrated to reach all the habitable parts of the planet. We have evolved to travel, to move on. Some modern instinctive behaviours may reflect this origin, for instance our pleasure at distant views from high hills; the delight of small children as they speed on their mini-scooters; even perhaps our willingness to pack into crowded underground trains - acceptable when moving, a source of anxiety when there is an unexpected halt in the tunnel.

For transport policy, the implication is that good quality mobility contributes to wellbeing, not just by ensuring access, but also for its own sake. While some people get their thrills from fast cars and motorbikes, growing numbers are taking to bicycles for both practical and exercise reasons. And pleasant street environments that give priority to pedestrians encourage walking. These slow modes are sustainable and should be encouraged.

21. Metz (2008b) Chapter 1. 



\section{REFERENCES}

Banister, D. and Bowling, A. (2004) 'Quality of life for the elderly: the transport dimension', Transport Policy, 11(2), pp.105-115.

Cairns, S., Sloman, L, Newson, C., Anable, J., Kirkbride, A. and Goodwin, P. (2008) 'Smarter Choices: assessing the potential to achieve traffic reduction using 'soft measures' ', Transport Reviews, 28(5), pp.593-618.

Competition Commission, 2008. Groceries Market Investigation: final report, paras 3.48-3.54, Competition Commission (London).

Crozet, Y. (2010) Driving forces of innovation in the transport sector. International Transport Forum, OECD, Paris.

DfT (2010) Public attitudes to road congestion, November 2009 to February 2010, Department for Transport, London.

Eurostat (2009) Panorama of Transport 2009 edition, Eurostat, Luxembourg.

JTRC (2010) Implementing congestion charging: summary and conclusion, Joint Transport Research Centre Round Table, February 2010, International Transport Forum, OECD, Paris.

Kaupilla, J. (2011) Ten stylised facts about household spending on transport, Statistical Paper 1/2011, International Transport Forum, OECD, Paris.

Lucas, K. and Jones, P. (2009) The Car in British Society: Trends and Challenges, The RAC Foundation, London.

Mackie, P. (2010) Cost-benefit analysis in transport: a UK perspective, Discussion Paper No 2010-16, International Transport Forum, OECD, Paris.

McKinnon, A. (2007) 'Decoupling of road freight transport and economic growth trends in the UK: an exploratory analysis', Transport Reviews, 27(1), pp. 37-64.

Mees, P. (2009) Transport for Suburbia, Earthscan, London

Metz, D. (2000) 'Mobility of older people and their quality of life', Transport Policy, 7(2), pp.149-152.

Metz, D. (2003) 'Transport policy for an ageing population', Transport Reviews, 23(4), pp. 375-386.

Metz, D. (2008a) 'The myth of travel time saving', Transport Reviews, 28(3), pp. 321-336.

Metz, D. (2008b) The Limits to Travel, Earthscan, London. 
Metz, D, (2010) 'Saturation of demand for daily travel', Transport Reviews, 30(5), pp. 659-674.

Millard-Ball, A. and Schipper, L. (2011) 'Are we reaching peak travel? Trends in passenger transport in eight industrialized countries', Transport Reviews [in press]

Osenton, T. (2004) The Death of Demand, Financial Times Prentice Hall, Upper Sadle River, NJ

Puentes, R. and Tomer, A. (2008) The Road Less Travelled: An analysis of Vehicle Miles Travelled Trends in the U.S., The Brookings Institution, Washington, DC.

Sansom T, Nash CA, Mackie PJ, Shires J, Watkiss P (2001) Surface Transport Costs and Charges: Final Report. For the Department of the Environment, Transport and the Regions. Institute for Transport Studies, University of Leeds, Leeds, July 2001.

Social Exclusion Unit, 2003. Making the connections: final report on transport and social exclusion, Office of the Deputy Prime Minister (London).

Schafer, A. and Victor, D. (2000) 'The future mobility of the world population', Transportation Research Part A, 34(3), pp.97-123.

Schwanen, T. and Paes, A. (2010) 'The mobility of older people - an introduction', Journal of Transport Geography, 18(5), pp. 591-595.

Vaupel, J. (2010) 'Biodemography of human ageing', Nature, 464, pp. 536-542. 
E International

International Transport Forum

2 rue André Pascal

75775 Paris Cedex 16

itf.contact@oecd.org

www.internationaltransportforum.org 